\title{
Effect of the consumption on buriti oil on the metabolism of rats induced by iron overload
}

\begin{abstract}
Jailane de Souza Aquino', Renata Leite Tavares², Larissa de Brito Medeiros ${ }^{3}$, Camila Cândida de Lima Martins' ${ }^{1}$, Débora Catarine Nepomuceno de Pontes Pessoa ${ }^{3}$, Tânia Lúcia Montenegro Stamford ${ }^{3}$
\end{abstract}

1 Departamento de Nutrição/Centro de Ciências da Saúde, Laboratório de Nutrição Experimental (Lanex) Universidade Federal da Paraíba (UFPB), João Pessoa, PB, Brasil

${ }^{2}$ Departamento de Nutrição/ Centro de Ciências da Saúde, UFPB, João Pessoa, PB, Brasil ${ }^{3}$ Departamento de Nutrição/Centro de Ciências da Saúde, Universidade Federal de Pernambuco (UFPE), Recife, PE, Brasil

\section{Correspondence to:}

Jailane de Souza Aquino

Universidade Federal da Paraíba

Laboratório de Nutrição Experimental

58041-900 - João Pessoa, PB, Brasil

lalaaquino@hotmail.com

Received on June/1/2015

Accepted on Aug/19/2015

DOI: 10.1590/2359-3997000000105

\begin{abstract}
Objectives: To compare the effect of the consumption of buriti oil and soybean oil on the metabolism of rats under stress induced by iron overload. Materials and methods: A total of 28 rats were randomized into control groups who consumed diet added of soybean (CS) or buriti oil (CB) and gavage with saline and two experimental groups who consumed diet added of soybean (ES) or buriti oil (EB) and daily gavage with iron II sulfate as stress inducer. The fatty acid profile of diets was analyzed. Body weight and diet consumption were evaluated every two days. The lipid profile and liver weight of animals were evaluated at the end of the experiment. Results: Diet added of soybean oil showed higher percentage of polyunsaturated fatty acids $(45.6 \%)$ and diet with buriti oil was rich in monounsaturated fatty acids (66.9\%). There were no differences in food intake, total cholesterol, HDL-cholesterol and LDL-cholesterol among groups ( $p>0.05$ ). However, animals fed with diet supplemented with buriti oil showed intermediate triglyceride levels (CB: $65 \mathrm{mg} / \mathrm{dL}$; EB: $68.7 \mathrm{mg} / \mathrm{dL}$ ) compared to ES group $(102.5 \mathrm{mg} / \mathrm{dL})$. The liver of rats from the CS group had higher weight $(2.06 \pm 0.2 \mathrm{~g})$ compared to the $\mathrm{CB}$ group $(1.56 \pm 0.1 \mathrm{~g}$ ). Conclusion: Buriti oil consumption was able to minimize some changes related to iron overload. Arch Endocrinol Metab. 2015;59(5):422-7
\end{abstract}

\section{Keywords}

Iron overload; oxidative stress; vegetable oils; Wistar rats

\section{INTRODUCTION}

$\mathrm{F}$ ree radicals are naturally generated in aerobic metabolism, behave as unstable reactive species and have in their last orbital a mismatch of electrons, being therefore capable of reacting with other reactive molecules (1). As protection against this effect, the organism has a defense mechanism comprising the action of endogenous enzymes or the action of antioxidants usually obtained from the consumption of foods, such as phenolic compounds, vitamin $\mathrm{C}$, beta-carotene and vitamin $\mathrm{E}(2)$. However, despite the proven antioxidant effect of these compounds, the antioxidant therapy in different pathologies may have some negative effects such as prooxidante action on lipids, proteins and DNA from excess of these compounds or indicate the presence of high oxygen concentrations (2-4).

The imbalance between the formation of reactive species and the body's defense mechanism generates a process called oxidative stress (5). Oxidative stress participates in the pathophysiology of dyslipidemia through the oxidation of LDL-C molecules. When these molecules are absorbed by the scavenger receptor, the appearance of foam cells and autoimmune reactions will take place, which will lead to the formation of thrombi that can trigger serious and sometimes fatal cardiovascular events (6). There are several ways to induce oxidative stress in animals in order to assess the impact of food consumption on this event. The use of dyslipidemic diet (7) over training (8) and iron overload (9) are among the most important. Excess iron in the body is associated with increased generation of free radicals by the Fenton reaction, which culminates in the formation of extremely reactive hydroxyl radical (10).

Due to the important effect of oxidative stress in several diseases, there has been a great interest on research of foods with antioxidant properties, especially vegetable oils. Nagajaru and Belur (11) used blends of coconut oil with peanut oil or olive oil in the diet of rats and obtained 
improvement in the action of antioxidant enzymes, reduced lipid peroxidation and susceptibility to the oxidation of LDL-cholesterol. Pieszka and cols. (12) observed a reduction in the activity of superoxide dismutase and glutathione peroxidase enzymes in animals fed with diets supplemented with strawberry and raspberry seed oils and concluded that these oils can improve the antioxidant status and thus reduce oxidative stress. These results have increased the population's interest in the consumption of vegetable oils with functional properties.

In this context, buriti oil has anti-inflammatory and healing applications (13), and is considered a functional food due to its high concentration of monounsaturated fatty acids and antioxidants, such as tocopherols and carotenoids $(14,15)$, being consumed by the population as an ingredient in various preparations (16). Given the above, this study aimed to compare the effect of buriti oil and soybean oil consumption on the metabolism of rats under oxidative stress induced by iron overload.

\section{MATERIALS AND METHODS}

Crude buriti oil was acquired from the popular trade of the city of Picos - PI, Brazil, which was extracted from mature fruits by cooking them in water for 20 minutes at temperature of $\pm 60^{\circ} \mathrm{C}$, subsequently separating the oily from the aqueous fraction. For all experiments, 3 L of crude oil were used, which were refined following degumming, neutralization, washing and drying steps according to methodology adapted from Aquino and cols (14). Soybean oil of the same trade mark was used to be added to the control diet, being purchased from a local supermarket.

Twenty-eight male Wistar rats aged \pm 21 days and initial weight of $\pm 60 \mathrm{~g}$ were used and kept in individual cages with water and diet ad libitum, temperature of $22 \pm 1{ }^{\circ} \mathrm{C}$, relative humidity between $50 \%$ and $55 \%$ and light/dark cycle of $12 \mathrm{~h}$.

The contents of macro and micronutrients in the diets offered to animals were calculated according to recommendations of the American Institute of Nutrition (AIN) (17). The animals were randomized and allocated into four groups: control group with daily gavage with saline and AIN 93M diet added of soybean oil (CS, $\mathrm{n}=$ $7)$, control group with daily gavage with saline and AIN 93M diet added of Buriti oil $(\mathrm{CB}, \mathrm{n}=7)$, experimental group with daily gavage with iron II sulfate and AIN 93M diet supplemented with soybean oil (ES; $\mathrm{n}=7$ ) and experimental group with daily gavage with iron II sulfate and AIN 93M diet supplemented with buriti oil $(\mathrm{EB} ; \mathrm{n}=7)$. The entire experimental protocol was approved by the Ethics Committee of Animal Research CEPA - UFPE under number 23076.001000/2010-29 and followed recommendations of the Brazilian College of Animal Experimentation - COBEA.

Diets for CS, ES, CB and EB groups (Table 1) were prepared on a weekly basis and offered daily in sufficient amounts to ensure ad libitum intake during the 17-day experimental period.

Table 1. Composition of diets offered to control and experimental groups

\begin{tabular}{lccc}
\hline Ingredients & $\begin{array}{c}\text { Amounts } \\
\mathbf{( g / 1 0 0 ~ g )}\end{array}$ & $\begin{array}{c}\text { CS and ES } \\
\text { Energy (Kcal) }\end{array}$ & $\begin{array}{c}\text { CB and EB } \\
\text { Energy (Kcal) }\end{array}$ \\
\hline Corn starch & 52.9 & 186.10 & 186.10 \\
Casein & 20.0 & 68.00 & 68.00 \\
Sucrose & 10.0 & 40.00 & 40.00 \\
Soybean or buriti oil & 7.0 & 63.0 & 63.0 \\
Cellulose & 5.0 & - & - \\
Mineral mix & 3.5 & - & - \\
Vitamin mix & 1.0 & - & - \\
D-L methionine & 0.3 & - & - \\
Choline bitartrate & 0.3 & - & - \\
Total & 100.00 & 357.10 & 357.10 \\
\hline
\end{tabular}

Control group fed with AIN 93M diet supplemented with soy oil and gavage with saline (CS); control group fed with AIN 93M diet supplemented with buriti oil and gavage with saline (CB); experimental group fed with AIN 93M diet supplemented with soybean oil and gavage with iron II sulfate (ES); experimental group fed with AIN 93M diet supplemented with buriti oil and gavage with iron II sulfate (EB).

Oxidative stress was induced by daily gavage for 17 days with iron II sulfate $(60 \mathrm{mg})$ for experimental groups, with a volume of $2 \mathrm{~mL} / 100 \mathrm{~g}$ body weight $(18,19)$. Animals' body weight and diet consumption were evaluated every two days during the 17-day experimental period.

The fatty acid profile of diets offered to animals was performed by esterification to obtain methyl esters (20). Gas chromatograph model GC-Master (Ciola \& Gregori Ltda., São Paulo, Brazil) with flame ionization detector was used to identify and quantify methyl esters. To perform the analysis, the following chromatographic conditions were met: polyethylene glycol fused silica column (Carbowax 20M) with $30 \mathrm{~m}$ in length, $0.53 \mathrm{~mm}$ in diameter and $0.25 \mu \mathrm{m}$ of stationary phase film thickness. Temperatures were adjusted to $150^{\circ} \mathrm{C}$ for the vaporizer, $200{ }^{\circ} \mathrm{C}$ for the detector and the oven was programmed at $80^{\circ} \mathrm{C}$ for 3 minutes, $10^{\circ} \mathrm{C} /$ minute up to $120^{\circ} \mathrm{C}$, remaining at $200^{\circ} \mathrm{C}$ for 6 minutes subsequently decreasing $3^{\circ} \mathrm{C} /$ minute up to $180^{\circ} \mathrm{C}$. The mobile phase was 
hydrogen, with flow rate of $5 \mathrm{~mL} /$ minute. The volume injected was $1 \mu \mathrm{m}$ with a split ratio of $1: 25$. The characterization of fatty acids was performed by comparing the mass spectrum obtained with that of standards that were also injected into the chromatograph (14).

After the 17-day experimental period and a 12 -h fasting period, the animals were anesthetized with ketamine $(75 \mathrm{mg} / \mathrm{kg})$ associated with xylazine $(10 \mathrm{mg} / \mathrm{kg})$ intramuscularly and blood was collected by direct cardiac puncture for the collection of $4 \mathrm{~mL}$ from each animal. Serum was obtained after centrifugation $(807 \times g / 10$ $\mathrm{min} / 20^{\circ} \mathrm{C}$ ) and maintained at temperature of $25^{\circ} \mathrm{C}$ for carrying out cholesterol (enzyme), HDL-c (polyethylene glycol-PEG), and triglyceride measurements (enzymatic) (Dolles Kit). After blood collection, the animals were euthanized by cervical dislocation and liver was removed, washed in $\mathrm{NaCl}$ solution $(0.9 \mathrm{~g} / 100 \mathrm{~mL})$, dried on absorbent paper and weighed.

All results are expressed as mean and standard deviation and submitted to analysis of variance (ANOVA) and Tukey-Kramer post-test using the Graph Pad Prism Software version 5.0, considering 5\% significance level.

\section{RESULTS}

The fatty acid profile found in diets added of soybean oil was quite distinct from that found in diet added of buriti oil because diet added of soybean oil had higher proportion of polyunsaturated fatty acids, especially linoleic acid, while diet added of buriti oil showed higher amounts of monounsaturated fatty acids, mainly oleic acid (Table 2).

Table 2. Fatty acid profile of AIN 93M diet added of soybean oil or modified by the addition of buriti oil

\begin{tabular}{lcc}
\hline \multirow{2}{*}{ Fatty acids } & \multicolumn{2}{c}{ Diets } \\
\cline { 2 - 3 } & Added of soybean oil & Added of buriti oil \\
\hline Myristic acid - C 14:0 & $19.6 \pm 0.02^{\mathrm{a}}$ & $12.8 \pm 0.04^{\mathrm{b}}$ \\
Palmitic acid - C 16:0 & $9.2 \pm 0.03^{\mathrm{b}}$ & $13.6 \pm 0.02^{\mathrm{a}}$ \\
Stearic acid - C18:0 & $3.9 \pm 0.03^{\mathrm{a}}$ & $2.7 \pm 0.02^{\mathrm{b}}$ \\
Total saturated fatty & $\mathbf{3 2 . 7} \pm 0.07^{\mathrm{a}}$ & $\mathbf{2 9 . 1} \pm 0.08^{\mathrm{b}}$ \\
acids (\%) & & \\
Oleic acid - C18:1 & $21.7 \pm 0.40^{\mathrm{b}}$ & $66.9 \pm 0.02^{\mathrm{a}}$ \\
Total monounsaturated & $\mathbf{2 1 . 7} \pm 0.40^{\mathrm{b}}$ & $\mathbf{6 6 . 9} \pm 0.32^{\mathrm{a}}$ \\
fatty acids (\%) & & \\
Linoleic Acid - C 18:2 & $40.7 \pm 0.02^{\mathrm{a}}$ & $4.0 \pm 0.04^{\mathrm{b}}$ \\
Linolenic Acid - C 18:3 & $4.9 \pm 0.02^{\mathrm{a}}$ & 0 \\
Total polyunsaturated & $\mathbf{4 5 . 6} \pm 0.04^{\mathrm{a}}$ & $\mathbf{4 . 0} \pm 0.04^{\mathrm{b}}$ \\
fatty acids (\%) & & \\
\hline
\end{tabular}

Different letters in the same line indicates statistical difference $(p<0.05)$ among samples.
Animals showed irregular food consumption (Figure 1A), considering that in the two weeks of experiment ES group (AIN 93M diet added of soybean oil and gavage with iron II sulfate) consumed $88.48 \pm 9.70 \mathrm{~g}$ in the first week and $108.14 \pm 10.1 \mathrm{~g}$ in the second week and CB group (AIN 93M diet added of buriti oil and gavage with saline) consumed $106.26 \pm 10.3 \mathrm{~g}$ diet in the first week and $121.72 \pm 10.6 \mathrm{~g}$ in the second week $(\mathrm{p}>0.05)$.

Body weight increased, on average, 72 g over the 17 days of experimental period (Figure 1B). Body weight varied among groups from $50.3 \pm 1.86$ to $54.5 \pm 5.85$ $\mathrm{g}$ on the first day of the experimental period (day 0), $65.4 \pm 8.66$ to $73.7 \pm 3.5$ in eighth day and from 107.9 \pm 12.0 to $118.6 \pm 8.9 \mathrm{~g}$ on the last day of the experimental period (day 17); however, with no difference among groups $(\mathrm{p}>0.05)$.

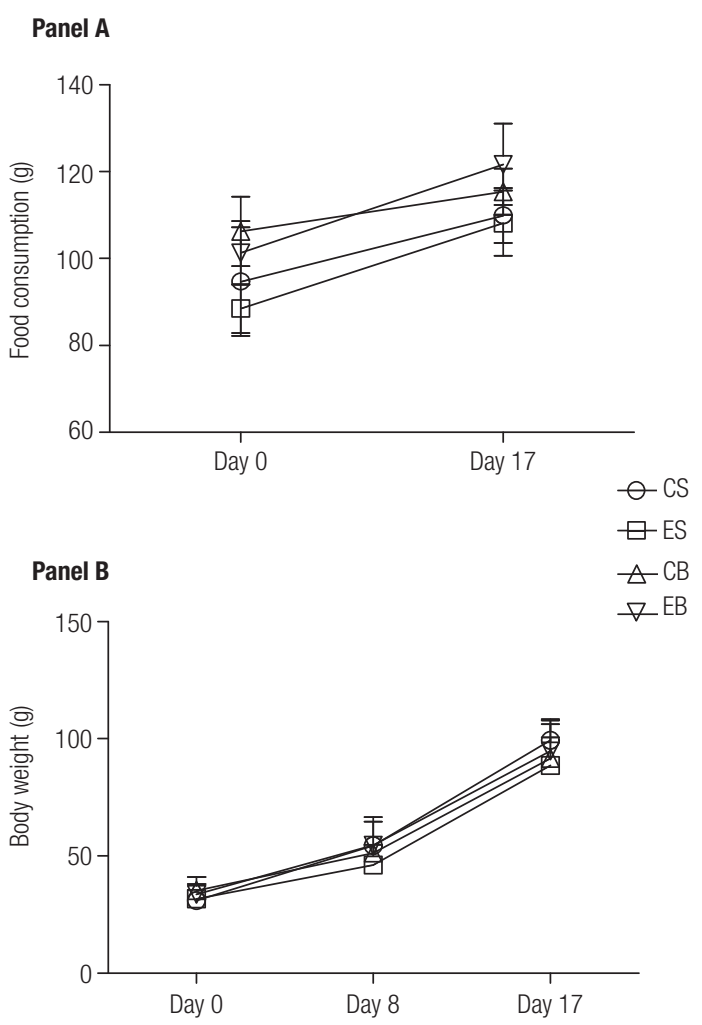

Figure 1. Food intake and body weight of rats submitted to iron overload and fed with diets added of soybean oil or buriti oil.

Control group fed with AIN 93M diet supplemented with soybean oil and gavage with saline (CS); control group fed with AIN 93M diet supplemented with buriti oil and gavage with saline (CB); experimental group fed with AIN 93M diet supplemented with soybean oil and gavage with iron II sulfate (ES); experimental group fed with AIN 93M diet supplemented with buriti oil and gavage with iron II sulfate (EB). * There was no significant difference among groups $(p>0.05)$.

There was difference in the weight of liver of rats from CS and CB groups $(2.06 \pm 0.2 \mathrm{~g}$ vs. $1.56 \pm 0.1 \mathrm{~g}$; $\mathrm{p}=0.006)$ as shown in figure 2 . 
There was no difference among groups for parameters total cholesterol, HDL-C and LDL-C. Total cholesterol values ranged from $81 \pm 6.6$ to $87.8 \pm 4.7 \mathrm{mg} /$ $\mathrm{dL}$; HDL cholesterol levels from $45.9 \pm 8.7$ to $52.2 \pm$ $2.7 \mathrm{mg} / \mathrm{dL}$ and LDL cholesterol from $15.02 \pm 2.9$ to $27.7 \pm 6.3 \mathrm{mg} / \mathrm{dL}$. A difference $(\mathrm{p}=0.004)$ in the triglyceride levels between CS $(41.2 \pm 22.0 \mathrm{mg} / \mathrm{dL})$ and ES groups $(95.2 \pm 27.2 \mathrm{mg} / \mathrm{dL})$ was found. However, groups that consumed diet supplemented with buriti oil showed similar triglyceride levels, of $65.0 \pm 17.8$ $\mathrm{mg} / \mathrm{dL}$ and $68.6 \pm 25.5 \mathrm{mg} / \mathrm{dL}$, respectively.

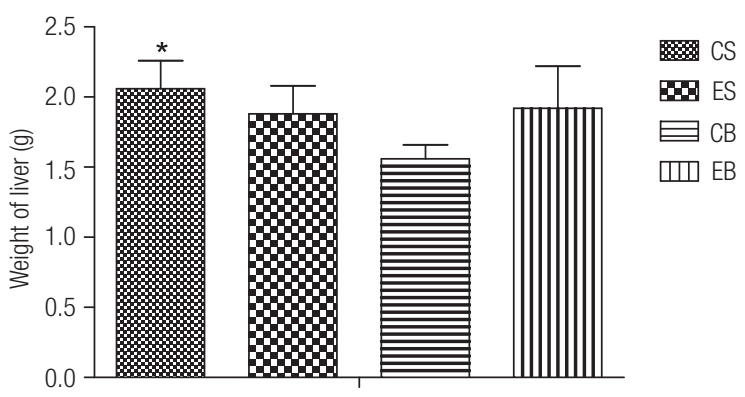

Figure 2. Liver weight of rats submitted to iron overload and fed with diets added of soybean or buriti oil.

Control group fed with AIN 93M diet supplemented with soybean oil and gavage with saline (CS); control group fed with AIN 93M diet supplemented with buriti oil and gavage with saline (CB); experimental group fed with AIN 93M diet supplemented with soybean oil and gavage with iron II sulfate (ES); experimental group fed with AIN 93M diet supplemented with buriti oil and gavage with iron II sulfate (EB). ${ }^{*} \mathrm{CS}$ vs. $\mathrm{CB}=$ there was significant difference $(p<0.05)$.

\section{DISCUSSION}

The control diet showed higher percentage of polyunsaturated fatty acids, especially linoleic acid and diet added of buriti oil was rich in monounsaturated fatty acids, mainly oleic acid. These results may be explained by the composition of vegetable oils used, as buriti oil has $4.6 \%$ saturated fatty acids, $91.6 \%$ monounsaturated fatty acids and $3.8 \%$ polyunsaturated fatty acids and soybean oil shows $31.7 \%$ saturated fatty acids, $23.6 \%$ monounsaturated fatty acids and $44.7 \%$ polyunsaturated fatty acids $(14,15,21)$.

Diets added of soybean oil and buriti oil of high concentration of polyunsaturated and monounsaturated fatty acids, respectively, should be consumed because they have antiatherogenic, vasodilator and antiplatelet action (22). The guidelines for proper fatty acids consumption suggest consumption according to the total caloric value of the diet from lipids with $7 \%$ of calories from saturated fatty acids, $15 \%$ from monoun- saturated fatty acids and 2-4 g/day of polyunsaturated fatty acids (23). Thus, it was observed that diet added of buriti oil showed adequate composition in relation to polyunsaturated fatty acids, according to the lipid consumption recommendation.

The increase in diet consumption justifies the weight gain of animals throughout the experimental period. With increasing age, animals started to consume greater amounts of diet, which led to weight gain. Almeida and cols. (22) observed no changes in food consumption of rats that ingested different lipid sources in their diets (soybean, fish and pork oil, butter or margarine). As observed by Yatmark and cols. (24), iron intake did not influence the weight gain of animals.

No changes were observed in the weight of liver of animals receiving iron overload by gavage (ES and $\mathrm{EB})$, although this organ is important in iron metabolism. These results corroborate those by Almeida and cols. (22), who also found no changes in the weight of liver of rats treated with iron and those who were not. However, the present results differ from those obtained by Yatmark and cols. (24), who found higher weight of liver of rats $(2.6 \pm 0.8)$ submitted to iron overload compared with the control group $(1.5 \pm 0.3)$. Importantly a reduction in the weight of liver of rats from $\mathrm{CB}$ group compared to those from CS was observed $(\mathrm{p}<$ 0.05 ), which can be explained by the difference in the composition of dietary lipids consumed by each group, which directly influences the weight of liver, fatty acid composition of liver and the deposition of antioxidant vitamins $A$ and $E$, which source is buriti oil $(15,21,25)$.

The presence of high percentage of linoleic fatty acid in soybean oil could indicate a reduction in total cholesterol of groups that consumed diet added of this oil (26). However, the present study did not detect any change in this parameter in the lipid profile of animals. Similarly, HDL-c and LDL-c levels were not affected by the consumption of buriti oil or iron overload. The results of the quantification of cholesterol and lipoproteins in this study differed from the results obtained by Aquino and cols. (15), in which a reduction in total cholesterol, LDL-C, VLDL-C and HDL-C levels was observed in rats that consumed refined buriti oil added to the diet in the percentage of $7 \%$ for 28 consecutive days.

Although no change in the LDL-c fraction among groups was observed, literature has shown that cells submitted to oxidative stress may have accumulation of oxidized LDL-c particles, a process called lipid per- 
oxidation (27). Then, an inflammatory response occurs, which ultimately results in endothelial dysfunction, platelet aggregation, formation of foam cells and thrombogenesis (28). This is the first step in atherosclerotic plaque formation, culminating in the emergence of atherosclerosis. It is noteworthy that among the various factors that influence the development of atherosclerosis, oxidative and inflammatory pathways are the most frequently observed and can effectively be involved in atherogenesis (29). However, Yatmark and cols. (24) found no difference in the weight of heart of animals induced to iron overload.

The triglyceride levels were increased in the ES group compared to the CS group. Iron overload induction might have caused an increase in triglyceride levels in the ES group, since there are data in literature indicating the presence of correlation between iron overload and elevated triglyceride levels $(30,31)$, as previously reported by Chaparro and cols. (32), who observed increase in triglyceride levels of animals submitted to oxidative stress induction. Due to that the fact that buriti oil is a source of monounsaturated fatty acids and vitamins A and E. (14,15,21) may have prevented this increase in the triglyceride levels even in the group that received iron overload (EB), as it showed intermediate and similar TAG levels when compared to $\mathrm{CB}$ group, indicating a possible action of this oil on this biochemical parameter. The maintenance of the levels of triglycerides in groups that consumed buriti oil added to the diet $(\mathrm{CB}, \mathrm{EB})$ can be justified by the mechanism of vitamin $\mathrm{A}$ and vitamin $\mathrm{E}$ absorption, which after absorption is transported by chylomicrons and lipoproteins containing other dietary lipids (such as triglycerides, phospholipids, cholesterol, and cholesteryl esters) and apolipoprotein B (apoB), which can quantitatively reduce the transport of these lipids $(33,34)$.

Reduced levels of triglycerides was observed in animals fed with refined buriti oil added to the diet, compared to healthy animals who consumed soybean oil or crude buriti oil, indicating that depending on the consumption duration and conditions, this type of oil can improve the levels of this parameter in healthy rats (15). In addition to intake of foods containing antioxidants such as phenolics, carotenoids, vitamin $\mathrm{C}$ and $\mathrm{E}$, the animal organism presents an important enzyme system with enzymes such as catalase, superoxide dismutase and glutathione peroxidase, which are involved in the neutralization of reactive oxygen species (ROS) formed during normal metabolism or pathogen, or from physical and chemical exogenous sources (35). However, the antioxidant therapy in different pathologies must be used with caution, since the pharmacological and physicochemical properties compounds are obtained from natural sources and may not have the expected effect in clinical trials $(3,4)$.

The consumption of buriti oil showed higher capacity to minimize some metabolic changes, even in animals submitted to iron overload, since it maintained liver weight and triglyceride levels in these animals, indicating that this oil may be a promising source of bioactive compounds to be inserted in the human diet.

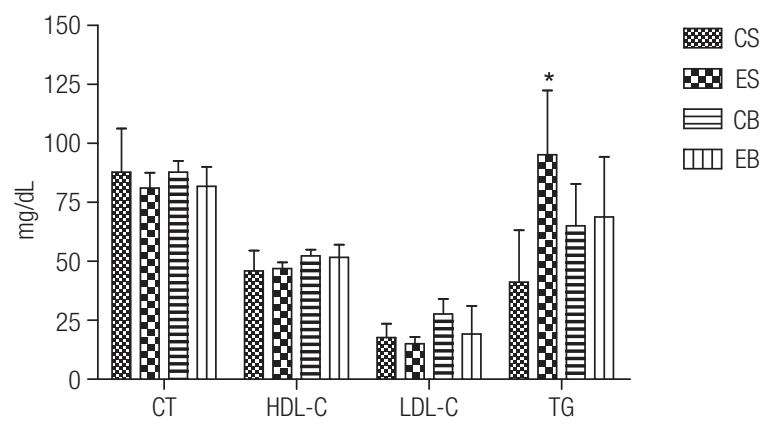

Figure 3. Triglycerides, total cholesterol and fractions of rats submitted to iron overload and fed with diets added of soybean or buriti oil.

Control group fed with AIN 93M diet supplemented with soybean oil and gavage with saline (CS); control group fed with AIN 93M diet supplemented with buriti oil and gavage with saline (CB); experimental group fed with AIN 93M diet supplemented with soybean oil and gavage with iron II sulfate (ES); experimental group fed with AIN 93M diet supplemented with buriti oil and gavage with iron II sulfate (EB). Different letters in the same line indicates statistical difference $(p<0.05)$ among groups. CT: total cholesterol; HDL-C: high density lipoprotein cholesterol; LDL: Iow density lipoprotein cholesterol; TG: triglycerides. * CS vs. ES = there was significant difference $(p<0.05)$.

Author contributions: Jailane de Souza Aquino helped conceiving the study, performed literature searches, wrote the manuscript and reviewed the final draft. Camila Cândida de Lima Martins and Larissa de Brito Medeiros performed data extraction and literature searches. Renata Leite Tavares performed statistical analyses of data and wrote the manuscript. Débora Catarine $\mathrm{Ne}$ pomuceno de Pontes Pessoa and Tânia Lúcia Montenegro Stamford conceived the study and reviewed the final draft.

Acknowledgements: none.

Disclosure: no potential conflict of interest relevant to this article was reported.

\section{REFERENCES}

1. Rajesha KP, Manjunatha H, Krishna V, Swamy BEK. Potential in vitro antioxidant and protective effects of Mesua ferrea Linn. 
bark extracts on induced oxidative damage. Ind Crops Prod. 2013;47:186-98.

2. Benfeito S, Oliveira C, Soares P, Fernandes C, Silva T, Teixeira J, et al. Antioxidant therapy: Still in search of the "magic bullet". Mitochondrion. 2013;13:427-35.

3. Zhang P, Osmye ST. Antioxidant and prooxidant roles for betacarotene, alpha-tocopherol and ascorbic acid in human lung cells. Toxicol In Vitro. 2001;15(1):13-24.

4. Hininger I, Wters R, Osman M, Garrel C, Fernhoz K, Roussel AM, et al. Acute prooxidant effects of vitamin C in EDTA chelation therapy and long-term antioxidant benefits of therapy. Free Radic Biol Med. 2005;38(12):1565-70.

5. Valko M, Rhodes $\mathrm{CJ}$, Moncol J, Izakivic M, Mazur M. Free radicals, metals and antioxidants in oxidative-stress induced cancer. Chem Biol Interact. 2006;160(1):1-40.

6. Siqueira AFA, Abdalla DSP, Ferreira SRG. LDL: da síndrome metabólica à instabilização da placa aterosclerótica. Arq Bras Endocrinol Metab. 2006;50(2):334-43.

7. Bruder-Nascimento T, Campos DHS, Alves C, Thomaz S, Cicogna AC, Cordellini S. Effects of chronic stress and high-fat diet on metabolic and nutritional parameters in Wistar rats. Arq Bras Endocrinol Metab. 2013;57/8:642-9.

8. Araújo GG, Gobatto $C A$, Hirata RDC, Hirata $M H$, Cavaglieri $C R$, Verlengia R. Respostas fisiológicas para detectar o overtraining. Rev Educ Fis UEM. 2008;19(2):275-89.

9. Siqueira EMA, Marin AMF, Cunha MSB, Fustioni AM, Sant'Ana LP, Arruda SF. Consumption of baru seeds [Dipteryx alata Vog.], a Brazilian savanna nut, prevents iron-induced oxidative stress in rats. Food Res Int. 2012;45(1):427-33.

10. Chen H, Lin B, Lukas TJ, Sueyoka G, Wu G, Neufeld AH. Changes in iron-regulatory proteins in the aged rodent neural retina. Neurobiol Aging. 2009;30(11):1865-76.

11. Nagajaru A, Belur LR. Rats fed blended oils containing coconut oil with groundnut oil or olive oil showed an enhanced activity of hepatic antioxidant enzymes and a reduction in LDL oxidation. Food Chem. 2008;108(3):950-7.

12. Pieszka M, Tombarkiewicz B, Romanc A, Migdał W, Niedziółkab J. Effect of bioactive substances found in rapeseed, raspberry and strawberry seed oils on blood lipid profile and selected parameters of oxidative status in rats. Environ Toxicol Pharmacol. 2013;36(3):1055-62.

13. Batista JS, Olinda RG, Medeiros VB, Rodrigues CMF, Oliveira AF, Paiva ES, et al. Atividade antibacteriana e cicatrizante do óleo de buriti Mauritia flexuosa L. Cien Rural. 2012;42(1):136-41.

14. Aquino JS, de Pontes Pessoa DCN, Araújo KLGV, Epaminondas OS, Schuler ARP, Souza AG, et al. Refining of buriti oil (Mauritia flexuosa) originated from the Brazilian cerrado: physicochemical, thermal-oxidative and nutritional implications. J Braz Chem Soc. 2012;23(2):212-9.

15. Aquino JS, Soares JKB, Magnani M, Stamford TCM, Mascarenhas RJ, Tavares RL, et al. Effects of Dietary Brazilian Palm Oil (Mauritia flexuosa L.) on Cholesterol Profile and Vitamin A and E Status of Rats. Molecules. 2015;20(5):9054-70.

16. Aquino JS, Pessoa DCNP, Oliveira CEV, Cavalheiro JMO, Stamford TLM. Processamento de biscoitos adicionados de óleo de buriti (Mauritia flexuosa L.): uma alternativa para o consumo de alimentos fontes de vitamina A na merenda escolar. Rev Nutr. 2012;25(6):765-74.

17. Reeves PG, Nielsen FH, Fahey GC. AIN-93 purified diets for laboratory rodents: final report of the American Institute of Nutrition ad hoc writing committee on the reformulation of the AIN-76A rodent diet. J Nutr. 1993;123(11):1939-51.
18. Õkva K, Tamoseviciute E, Ciziute A, Pokk P, Ruksenas O, Nevalainen T. Refinements for intragastric gavage in rats. Scand J Lab Anim Sci. 2006;33(4):243-52.

19. Mendes JFR, Arruda SF, Siqueira EMA, Ito MK, Silva EFS. Iron status and oxidative stress biomarkers in adults: a preliminary study. Nutrition. 2009;25 (4):379-84.

20. Hartman L, Lago RCA. Rapid preparation of fatty acid methyl esters from lipids. Lab Practice. 1973;22:475-77.

21. Medeiros MC, Aquino JS, Soares JKB, Figueiroa EB, Mesquita $H M$, Pessoa DCN, et al. Buriti oil (Mauritia flexuosa L.) negatively impacts somatic growth and reflex maturation and increases retinol deposition in young rats. Int J Dev Neurosci. 2015;46:7-13.

22. Almeida MEF, Queiroz JH, Costa NMB, Matta SLP. Lipídeos séricos e morfologia hepática de ratos alimentados com diferentes fontes lipídicas (óleo de soja, gordura de peixe e porco, margarina e manteiga). Rev Nutr. 2011; 24(1):143-52.

23. Santos RD, Gagliardi ACM, Xavier HT, Magnoni CD, Cassani R, Lottenberg AM, et al. Sociedade Brasileira de Cardiologia. I Diretriz sobre o Consumo de Gorduras e Saúde Cardiovascular. Arq Bras Cardiol. 2013;100(1Supl.3):1-40.

24. Yatmark P, Morales NP, Chaisri U, Wichaiyo S, Hemstapat W, Srichairatanakool, et al. Iron distribution and histopathological characterization of the liver and heart of $\beta$-thalassemic mice with parenteral iron overload: Effects of deferoxamine and deferiprone. Exp Toxicol Pathol. 2014;66(7):333-43.

25. Papadomichelakis G, Fegeros EZK. Dietary induced changes in liver composition and weight of fattening rabbits. Livestock Sci. 2012;144:190-6.

26. Giroldo ML, Alves AS, Baptista F. Doença arteriosclerótica: uma patologia multifatorial. Rev Saúde Biol. 2007;2(1):32-41.

27. Ferreira ALA, Correa CR, Freire CMM, Moreira PL, Bechieri-Ronchi $\mathrm{CB}$, Reis RAS, et al. Síndrome metabólica: atualização de critérios diagnósticos e impacto do estresse oxidativo na patogênese. Rev Bras Clin Med. 2011;9(1):54-61.

28. Silva DC, Cerchiaro G, Honório KM. Relações patofisiológicas entre estresse oxidativo e arteriosclerose. Quim Nova. 2011;34(2):300-5.

29. Giacomini MM, Hahn S, Siqueira LO. Análise da correlação do perfil lipídico e dano oxidativo em pacientes diabéticos. Rev Cienc Farm Básica Apl. 2013;34(2):251-5.

30. Silva M, Silva ME, de Paula H, Carneiro CM, Pedrosa ML. Iron overload alters glucose homeostasis, causes liver steatosis, and increases serum triacylglycerols in rats. Nutrition Res. 2008;28:391-8.

31. Pari L, Karthikeyan A, Karthika P, Rathinam A. Protective effects of hesperidin on oxidative stress, dyslipidemia and histological changes in iron-induced hepatic and renal toxicity in rats. Toxicol Rep. 2015;2:46-55.

32. Chaparro LC, Aguillar AK, Silva LECM, Freitas SF, Alceu AJ Jr. Efeitos da suplementação de lecitina de soja no perfil lipídico hepático e no estresse oxidativo de ratos que receberam dieta deficiente em colina e metionina. Nutrire. 2011;36(Suppl):24.

33. Meydani M, Kwan P, Band M, Knight A, Guo W, Goutis J, et al. Long-term vitamin $E$ supplementation reduces atherosclerosis and mortality in LdIr___ mice, but not when fed Western style diet. Atherosclerosis. 2014;233:196-205.

34. Harrison EH. Mechanisms involved in the intestinal absorption of dietary vitamin A and provitamin A carotenoids. Biochim Biophys Acta. 2012;1821:70-7.

35. Gostner JM, Becker K, Ueberral F, Fuchs D. he good and bad of antioxidant foods: An immunological perspective. Food Chem Toxicol. 2015;80:72-9. 